\title{
Spawanie stali ulepszanej ciepInie na przykładzie S690QL
}

\author{
Welding of heat-treated steel on the example of S690QL
}

\section{Streszczenie}

W pracy przedstawiono technologię spawania stali ulepszanej cieplnie na przykładzie S690QL. Część badawcza pracy prezentuje wszystkie istotne parametry i założenia niezbędne do wykonania złącza spawanego. Dodatkowo zawarte zostały wyniki badań, które przeprowadzono na specjalnie przygotowanych próbkach. Dla porównania zestawiono ze sobą dwa złącza czołowe o grubości $12 \mathrm{~mm}$ i $50 \mathrm{~mm}$ oraz złącze pachwinowe o grubości $40 \mathrm{~mm}$. Zakres badań obejmuje badania nieniszczące takie jak: wizualne, penetracyjne, ultradźwiękowe i radiograficzne oraz badania niszczące tj. próby rozciągania, zginania, udarności, ocenę makrostruktury oraz pomiar twardości złącza.

Słowa kluczowe: złącze spawane; badania nieniszczące; własności mechaniczne

\begin{abstract}
The paper presents the technology for welding of heat-treated steel on the example of S690QL steel. . Part of the research work shows all relevant parameters and assumptions necessary for the implementation of the welded joint. In addition, part of the research included the results of studies that were conducted on specially prepared specimens. For comparison two butt welds with a thickness of $12 \mathrm{~mm}$ and $50 \mathrm{~mm}$ and a fillet weld thickness of $40 \mathrm{~mm}$ are presented. The scope of research includes the non-destructive testing such as visual test, penetration test, ultrasonic test, radiographic test and destructive tests, which include: tensile test, bending test, impact test, macro test and measurement of hardness.
\end{abstract}

Keywords: welding joint; non-destructive testing; mechanical properties

\section{Wstęp}

Stale ulepszone cieplnie są to stale drobnoziarniste niskostopowe, w których dzięki dobraniu odpowiedniego składu chemicznego, warunków walcowania oraz obróbki cieplnej można uzyskać granicę plastyczności w zakresie $450 \div 1000 \mathrm{MPa}[1]$.

Obecnie wprowadza się nową technologię wytwarzania stali ulepszanych cieplnie, która polega na bezpośrednim hartowaniu blachy po jej odwalcowaniu bez ponownego nagrzewania. Dzięki tej technologii uzyskuje się granicę plastyczności stali większą o ok. $130 \mathrm{MPa}$, w porównaniu do konwencjonalnego ulepszania cieplnego przy tym samym składzie chemicznym stali. Przy zastosowaniu tej metody można utworzyć stal ulepszoną cieplnie, która posiada o 0,05\% mniejszy równoważnik węgla, a tym samym odznacza się lepszą spawalnością w porównaniu ze stalą wyprodukowaną według dotychczasowej techniki [2].

Ze względu na to, że dla stali ulepszonych cieplnie wartości równoważnika węgla są wyższe niż dla stali walcowanych normalizująco lub normalizowanych, ulegają one w strefie wpływu ciepła większemu utwardzeniu, przez co należy przestrzegać zasad spawania, aby zapobiec powstaniu zimnych pęknięć. Jeżeli równoważnik węgla dla stopiwa będzie większy od równoważnika węgla dla materiału rodzimego, temperaturę wstępnego podgrzania należy dobrać zgodnie ze składem chemicznym stopiwa [3].

Obniżenie wytrzymałości strefy wpływu ciepła wynikające z nagrzania złącza do temperatury przekraczającej temperaturę odpuszczania stali, a także występowanie przy końcu SWC obszaru o obniżonej twardości powoduje, że powinno się kontrolować maksymalną temperaturę międzyściegową oraz ilość wprowadzonego ciepła [4]. Tym samym ogranicza się szerokość tego obszaru oraz stopień jego zmiękczenia.

Materiały dodatkowe do spawania stali ulepszonej cieplnie dobiera się w taki sposób, aby uzyskać stopiwo o granicy plastyczności dostosowanej do granicy plastyczności określonej stali. W przypadku stali o wyższej granicy plastyczności do spawania zaleca się stosowanie spoiw, których granica plastyczności stopiwa jest niższa od granicy plastyczności dla materiału rodzimego. Jest to warunek istotny dla wykonywania ściegów graniowych, ponieważ występuje duża skłonność do pojawienia się zimnych pęknięć. Do wykonania warstw wypełniających i licowych stosuje się drut, który daje stopiwo o nieco mniejszej wytrzymałości od materiału rodzimego. Wskutek dużego stopnia wymieszania można uzyskać wyższe własności wytrzymałościowe dla całego złącza w porównaniu do materiału rodzimego.

Dr inż. Anna Pocica - Politechnika Opolska, inż. Maciej Obara - Famet S.A.

Autor korespondencyjny/Corresponding author. a.pocica@po.opole.pl 


\section{Badania własne}

Badaniom poddano złącza doczołowe i teowe ze stali S690QL (tabl. I). Złącza wykonano metodą MAG (135) w osłonie mieszanki gazowej $82 \% \mathrm{Ar}$ i $18 \% \mathrm{CO}_{2}$, drutem Bohler $\mathrm{X}$ 70-IG EN ISO 16834-A: G Mn3NiCrMo, o średnicy 1,2 mm. Temperatura podgrzewania wstępnego wynosiła min. $100^{\circ} \mathrm{C}$, temperatura międzyściegowa złączy doczołowych $200{ }^{\circ} \mathrm{C}$, a teowych $250{ }^{\circ} \mathrm{C}$. Parametry spawania przedstawiono w tablicy II. W przypadku złączy doczołowych wymiary blach wynosiły 12 × 300 x 350 mm oraz 50 x 300 x 350 mm natomiast w przypadku połączenia teowego 40 x 350 x $350 \mathrm{~mm}$ przy podstawie oraz $40 \times 150 \times 350 \mathrm{~mm}$ w pionie.

Tablica I. Skład chemiczny i własności badanej stali

Table I. Chemical composition and machanical properties of tested steel

\begin{tabular}{|c|c|c|c|c|c|c|c|}
\hline \multicolumn{7}{|c|}{ Skład chemiczny stali [\%] } \\
\hline $\mathrm{C}$ & $\mathrm{Si}$ & $\mathrm{Mn}$ & $\mathrm{P}$ & $\mathrm{S}$ & $\mathrm{Cr}$ & $\mathrm{Ni}$ & $\mathrm{Mo}$ \\
\hline 0,17 & 0,28 & 1,03 & 0,01 & 0,003 & 0,59 & 0,47 & 0,32 \\
\hline $\mathrm{Al}$ & $\mathrm{N}$ & $\mathrm{V}$ & $\mathrm{Nb}$ & $\mathrm{Ti}$ & $\mathrm{B}$ & $\mathrm{Cu}$ & $\mathrm{C}_{\text {eq }}$ \\
\hline 0,051 & 0,0089 & 0,04 & 0,004 & 0,004 & 0,0031 & 0,12 & 0,57 \\
\hline \multicolumn{7}{|c|}{ Właściwości mechaniczne } \\
\hline $\mathrm{R}_{\mathrm{m}} \mathrm{MPa}$ & \multicolumn{1}{|c|}{$\mathrm{R}_{\mathrm{e}} \mathrm{MPa}$} & $\mathrm{A}_{5,} \%$ & Udarność, J \\
\hline \multicolumn{7}{|c|}{855} & \multicolumn{2}{c|}{15,6} & 139 \\
\hline
\end{tabular}

Zgodnie z PN-EN ISO 15614-1 [5] zakres badań złącza doczołowego obejmował badania nieniszczące: wizualne, penetracyjne oraz radiograficzne w przypadku blach o grubości $12 \mathrm{~mm}$ i ultradźwiękowe w przypadku blach o grubości $50 \mathrm{~mm}$. Badania obejmowały 100\% długości złącza oraz SWC od strony lica i grani. Przeprowadzono również próby rozciągania, zginania, udarności, ocenę makrostruktury spoiny oraz twardości. Dla złącza teowego wykonano badania wizualne, penetracyjne, obejmujące 100\% długości złącza i SWC od strony lica 1 i lica 2, a także ocenę makrostruktury oraz pomiary twardości.

Badania wizualne, przeprowadzone przy użyciu standardowego wyposażenia, wykazały, że wszystkie złącza spełniają klasę jakości $B$.

Badania penetracyjne przeprowadzono metodą penetracji barwnej preparatami firmy DIFFU-THERM w temperaturze pokojowej. Wszystkie złącza spełniały poziom jakości B, zgodnie z PN-EN ISO 23277 [6].

Dla złącza o grubości $12 \mathrm{~mm}$ wykonano badania rentgenowskie, a dla złącza o grubości $50 \mathrm{~mm}$ badania ultradźwiękowe.

Badania rentgenowskie wykonano aparatem MXR200. Napięcie przyspieszające wynosiło 160 kV, a czas ekspozycji 2,5 min. Stwierdzono, że złącze spełnia poziom jakości B, zgodnie z PN-EN ISO 23277.

Badania ultradźwiękowe prowadzono metodą OWR defektoskopem Olympus EPOCH 650. Stwierdzono brak wskazań przekraczających poziom rejestracji, a złącze spełniało poziom jakości B.
Próby rozciągania wykonano na zrywarce ZD40 NR 282/53 o zakresie siłomierza $300 \mathrm{~N}$, a udarności na młocie WPM NR 423/48. Zginanie wykonano trzpieniem o średnicy $40 \mathrm{~mm}$, przy rozstawie podpór $70 \mathrm{~mm}$. Próba udarności została przeprowadzona na próbkach z karbem Charpy, w temperaturze $-40{ }^{\circ} \mathrm{C}$ i przy minimalnej pracy łamania $30 \mathrm{~J}$. Wartości średnie badań mechanicznych przedstawiono w tablicy III.

Makrostrukturę złączy określono stosując odczynnik Adlera, przy powiększeniu 4x. Zaobserwowane struktury przedstawiono na rysunkach $1 \div 3$.

Tablica III. Własności mechaniczne złączy spawanych Table III. Mechanical properties of welding joint

\begin{tabular}{|c|c|c|c|c|}
\hline Rodzaj złącza & $\begin{array}{c}\mathbf{R}_{\mathrm{m}} \\
{[\mathrm{MPa}]}\end{array}$ & $\begin{array}{c}\text { Miejsce } \\
\text { zerwania }\end{array}$ & $\begin{array}{c}\text { Kat } \\
\text { zginania } \\
\mathbf{1 8 0 ^ { \circ }}\end{array}$ & $\begin{array}{c}\text { Praca } \\
\text { tamania } \\
{[\mathrm{J}]}\end{array}$ \\
\hline Doczołowe g $=12 \mathrm{~mm}$ & 772 & spoina & brak wad & 87 \\
\hline Doczołowe g = 50 mm & 798 & spoina & brak wad & 91 \\
\hline
\end{tabular}

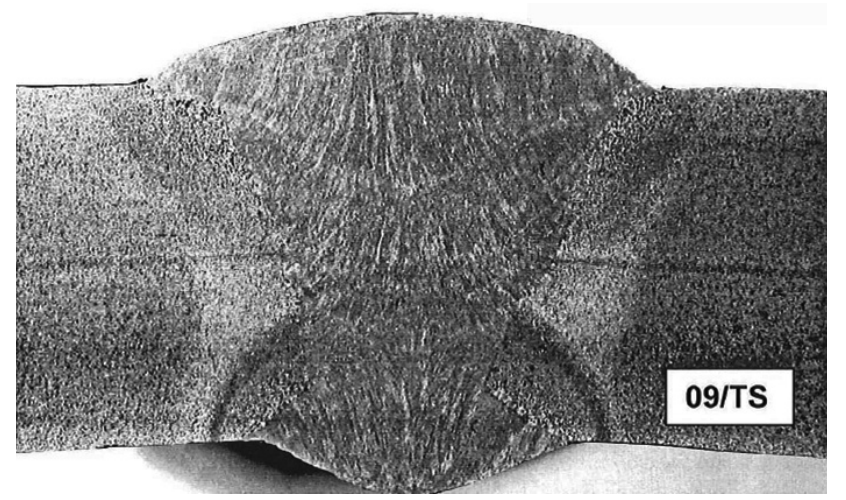

Rys. 1. Makrostruktura złącza o grubości $12 \mathrm{~mm}$

Fig. 1. Macrostructure of the joint with a thickness of $12 \mathrm{~mm}$

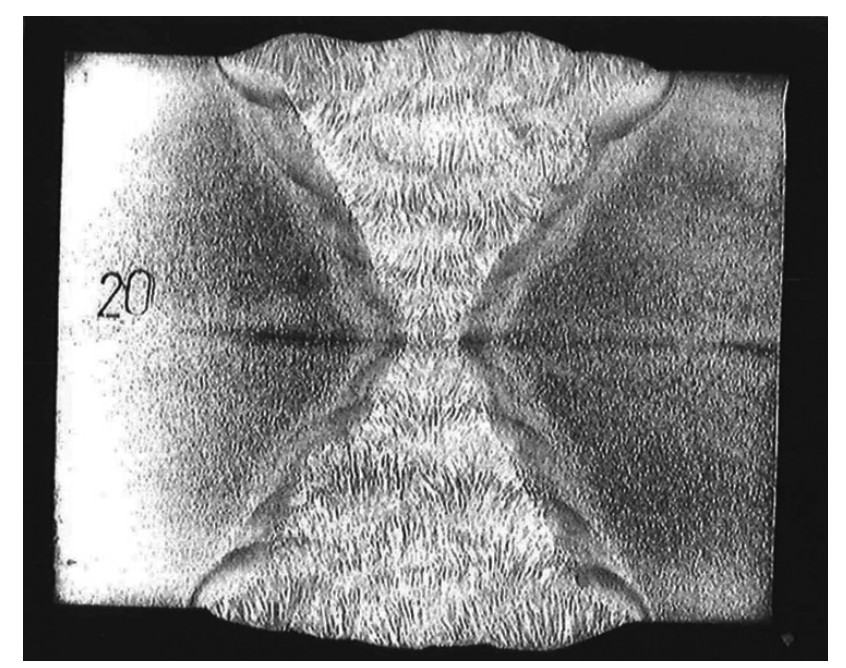

Rys. 2. Makrostruktura złącza o grubości $40 \mathrm{~mm}$

Fig. 2. Macrostructure of the joint with a thickness of $40 \mathrm{~mm}$

Tablica II. Parametry spawania

Table II. Welding parameters

\begin{tabular}{|c|c|c|c|c|c|}
\hline Rodzaj złącza & Prąd spawania [A] & Napięcie prądu [V] & $\begin{array}{c}\text { Natężenie przepły- } \\
\text { wu gazu [l/min] }\end{array}$ & Pozycja spawania & Rodzaj prądu \\
\hline Doczołowe $\mathrm{g}=12 \mathrm{~mm}$ & $110 \div 245$ & $19 \div 27$ & $13 \div 15$ & PA & $\mathrm{DC}+$ \\
\hline Doczołowe $\mathrm{g}=50 \mathrm{~mm}$ & $105 \div 215$ & $15 \div 27$ & $15 \div 17$ & PA & $\mathrm{DC}+$ \\
\hline Teowe $\mathrm{g}=40 \mathrm{~mm}$ & $220 \div 240$ & $26 \div 29$ & $14 \div 16$ & PB & $\mathrm{DC}+$ \\
\hline
\end{tabular}



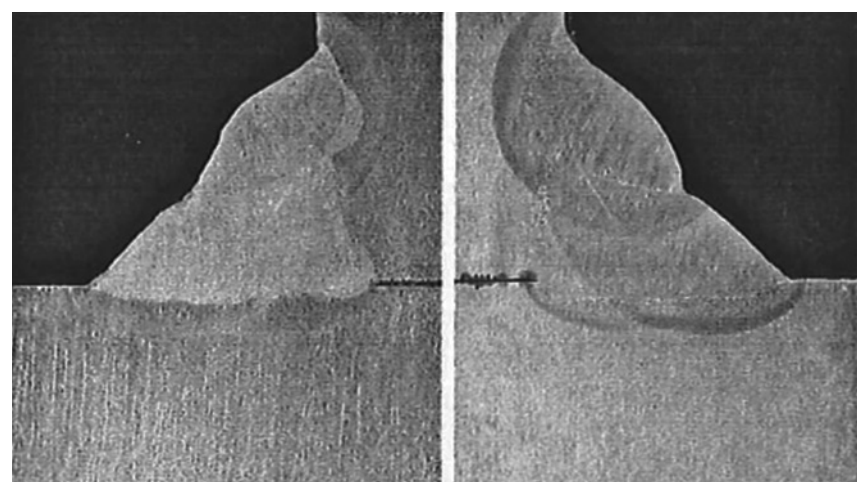

Rys. 3. Makrostruktura złącza o grubości $50 \mathrm{~mm}$

Fig. 3. Macrostructure of the joint with a thickness of $50 \mathrm{~mm}$

Na podstawie obserwacji stwierdzono, że budowa wewnętrzna spoiny i SWC jest prawidłowa, bez widocznych niezgodności spawalniczych, a złącze spełnia poziom jakości B.

Badania twardości wykonano na twardościomierzu Vickersa ZWICK. Dla złączy o grubości 12 i $40 \mathrm{~mm}$ pomiary prowadzono w dwóch liniach pomiarowych, a dla złącza o grubości $50 \mathrm{~mm}$, w trzech liniach. W każdym obszarze złącza wykonano po 3 pomiary. Wyniki badań przedstawiono na rysunku 4.

Na podstawie wstępnej instrukcji spawania oraz uzyskanych wyników badań opracowano instrukcje WPS dla wszystkich złączy.

\section{Analiza wyników badań}

Przeprowadzone badania statyczne pozwoliły stwierdzić, że w przypadku próby rozciągania próbek wartości granicy wytrzymałości są podobne. Granica wytrzymałości $R_{m}$ oscy-

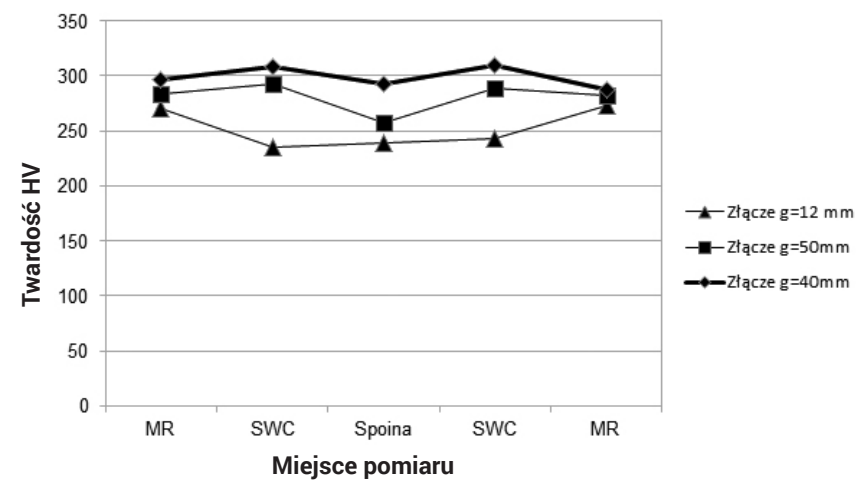

Rys. 4. Rozkład twardości w przekroju poprzecznym badanych złączy Fig. 4. Hardness distribution in the cross-section of tested joints

luje między $770 \div 800 \mathrm{MPa}$, przy wartościach dopuszczalnych $770 \div 940 \mathrm{MPa}$. W próbie zginania nie wykryto żadnych nieprawidłowości. Maksymalna udarność wynosiła $103 \mathrm{~J}$, charakter przełomów był plastyczny lub mieszany. Wszystkie wyniki mieszczą się w wytycznych normy. Badanie twardości wykazało zbliżoną twardość wszystkich złączy. Wyniki spełniają kryteria PN-EN ISO 9015-1.

Po zestawieniu ze sobą wszystkich wyników badań można zauważyć, że wszystkie próbki muszą zostać podgrzane do pewnej temperatury przed spawaniem. Dla stali S690QL zaleca się stosować podgrzewanie przed spawaniem już od grubości równej $10 \mathrm{~mm}$. Następnym istotnym aspektem jest temperatura międzyściegowa, która w przypadku tej stali nie może przekroczyć $250^{\circ} \mathrm{C}$, w przeciwnym razie może dojść do znacznego osłabienia własności mechanicznych złącza. Badania makroskopowe wskazują na to, że złącza spawane spełniają poziom jakości B wg PN-EN ISO 5817 [7]. Oznacza to, że spoina została wykonana w sposób prawidłowy.

\section{Podsumowanie}

Wyniki wszystkich przeprowadzonych badań były do siebie podobne, co jednoznacznie potwierdza fakt, że technologie spawania i parametry zostały dobrane prawidłowo. Jednakże podczas spawania stali S6900L należy zwracać szczególną uwagę na to, aby nie wprowadzić do spoiny zbyt dużej ilości ciepła, ponieważ może to doprowadzić do drastycznego spadku własności mechanicznych połączenia spawanego, takich jak obniżenie granicy plastyczności $R_{e}$ i granicy wytrzymałości $R_{m}$. Może również dojść do znacznego rozrostu ziarna i jego iglastej budowy, co jest niepożądane.

\section{Literatura}

[1] Tasak E.: Spawalność stali, Fotobit, Kraków, 2002.

[2] Tasak E.: Metalurgia spawania, Wyd. Jak, Kraków, 2008.

[3] Brózda J.: Stale konstrukcyjne i ich spawalność, Instytut Spawalnictwa, Gliwice, 2008.

[4] Makles K., Spawalność i wybrane właściwości złączy stali ulepszanych cieplnie. Przegląd Spawalnictwa nr 8, 2014, s.19-25

[5] PN-EN ISO 15614-1: Specyfikacja i kwalifikowanie technologii spawania metali -- Badanie technologii spawania -- Część 1: Spawanie łukowe i gazowe stali oraz spawanie łukowe niklu i stopów niklu
[6] PN-EN ISO 23277:2015-05: Badanie nieniszczące spoin -- Badanie penetracyjne spoin -- Poziomy akceptacji tytanu i ich stopów (z wyjątkiem spawanych wiązką) -- Poziomy jakości według niezgodności spawalniczych

[7] PN-EN ISO 5817: Spawanie -- Złącza spawane ze stali, niklu, tytanu i ich stopów (z wyjątkiem spawanych wiązką) -- Poziomy jakości według niezgodności spawalniczych 